\title{
Implementation Level of Health Management Information System Program in Governmental Hospitals of Ethiopia
}

\author{
Tesfamichael Alaro ${ }^{1,}$ *, Samuel Sisay ${ }^{2}$, Senait Samuel ${ }^{2}$ \\ ${ }^{1}$ Health Economics, Management and Policy, Jimma University, Jimma, Ethiopia \\ ${ }^{2}$ Information Science, Jimma University, Jimma, Ethiopia
}

Email address:

tesfamichael.alaro@ju.edu.com (T.Alaro), sis.samuel@gmail.com (S. Sisay), senaits73@gmail.com (S. Samuel)

${ }^{*}$ Corresponding author

\section{To cite this article:}

Tesfamichael Alaro, Samuel Sisay, Senait Samuel. Implementation Level of Health Management Information System Program in Governmental Hospitals of Ethiopia. International Journal of Intelligent Information Systems. Vol. 8, No. 2, 2019, pp. 52-57. doi: $10.11648 /$ j.ijiis.20190802.13

Received: January 11, 2019; Accepted: April 10, 2019; Published: July 10, 2019

\begin{abstract}
Background: The Ethiopian Health Management Information System (HMIS) has been implemented since 2008 to improve the provision of health services, and ultimately, to improve health status of the population. Currently, information revolution is one of the transformation agenda in Ethiopia. Ironically, as in many low-income countries, lack of reliable data and grossly inadequate appreciation and use of available information for planning and management of health services were also true for the HMIS of Ethiopia. This, therefore, to assess the level of implementation HMIS program and utilization of data generated in governmental hospitals of western Oromia, Ethiopia. Methods and Material: The study was conducted in seven randomly selected Western Oromia Hospitals. A descriptive facility based cross-sectional study design with quantitative and qualitative data collection method was employed. The final sample size was calculated to be 620 . The samples were selected by simple random sampling technique. The collected data was checked for any inconsistencies and analyzed by fitting multivariate logistic regression in SPSS version 17.0 statistical package. Result: Of the total 620 sampled population, 569 participated with an overall response rate of $91.8 \%$. Of the total respondents, $504(88.6 \%)$ were ever implemented HMIS tools to collect patients data in their respective hospital. Of which, only $85(16.9 \%)$ perceived that they regularly analyze the collected data into meaningful information. Despite the inspiring message by H. E. Dr. Kesetebirhan Admasu former Minister, Federal Ministry of Health, Ethiopia "....health information is much more than collecting figures. Data have no value in themselves; value and relevance come after data management and analysis...the process whereby data are transformed into information and knowledge for action." In this study, only $221(43.8 \%)$ reported they used HMIS generated information for a different actions in their respective hospitals. This study revealed that the major challenges for consistent implementation and use of HMIS were incomplete data filling 174 (34.5\%) followed by a shortage of trained human power 158 (31.3\%) in HMIS. Furthermore, there was statistically significant association between consistent implementation of HMIS program with presence of HMIS reporting format, regular monitoring and evaluation, trained staffs and having regular feedback. Conclusions: In this study, more than three-fourths of participants perceived they were ever implemented HMIS to generate information. But, less than half of participants reported they used the output of HMIS generated information for reporting, planning and decision making at local level.
\end{abstract}

Keywords: Health Management Information System, Implementation Level, Governmental Hospital, Ethiopia

\section{Introduction}

An enhanced and synchronized health reporting system is critical for health system strengthening; since, it can generate timely information for proper planning, monitoring and evaluation of service delivery at all levels of the health system
[1]. However, in most developing countries, particularly in sub-Saharan Africa, health services reporting has been dominated by paper-based data collection and storage systems that tend to generate incomplete and inaccurate reports [2].

Development of an equitable and acceptable standard of health service system that will reach all segments of the population within the limits of resources was specified as the 
goal of health systems [3]. Health Management Information System is one of seven components of the Health Sector Development Program three (HSDP III) of Ethiopia where, the HSDP III lays out the importance of HMIS as the backbone of effective healthcare delivery [4].

A lot of data is generated from patients in the health sector every day. Hence, timely interpretation of data is vital to intervene successfully. Moreover, reliable and valid health information is needed for evidence based decision-making [15]. To this end, the development of web-based health information systems like electronic HMIS and print HMIS has opened a new chapter for improving health reporting in the developed world and this is slowly taking root in most developing countries [5].
In Ethiopia Information and communications technology (ICT), the infrastructure to support it and the trained staff to use it are all weak at district level. According to the Federal Ministry of Health (FMOH) report $60 \%$ of districts have no computers. Sixty percent of districts reported having electricity and only $9 \%$ of districts reported having HMIS staff with basic computer skills [6].

Conceptual Frame Work of Reviewed Literature

An effective implementation of HMIS ensures uninterrupted availability and rational use of information for future planning and informed decision making. Accordingly, this study was focused on assessment of the implementation level of HMIS program in governmental hospitals of western Oromia, Ethiopia.

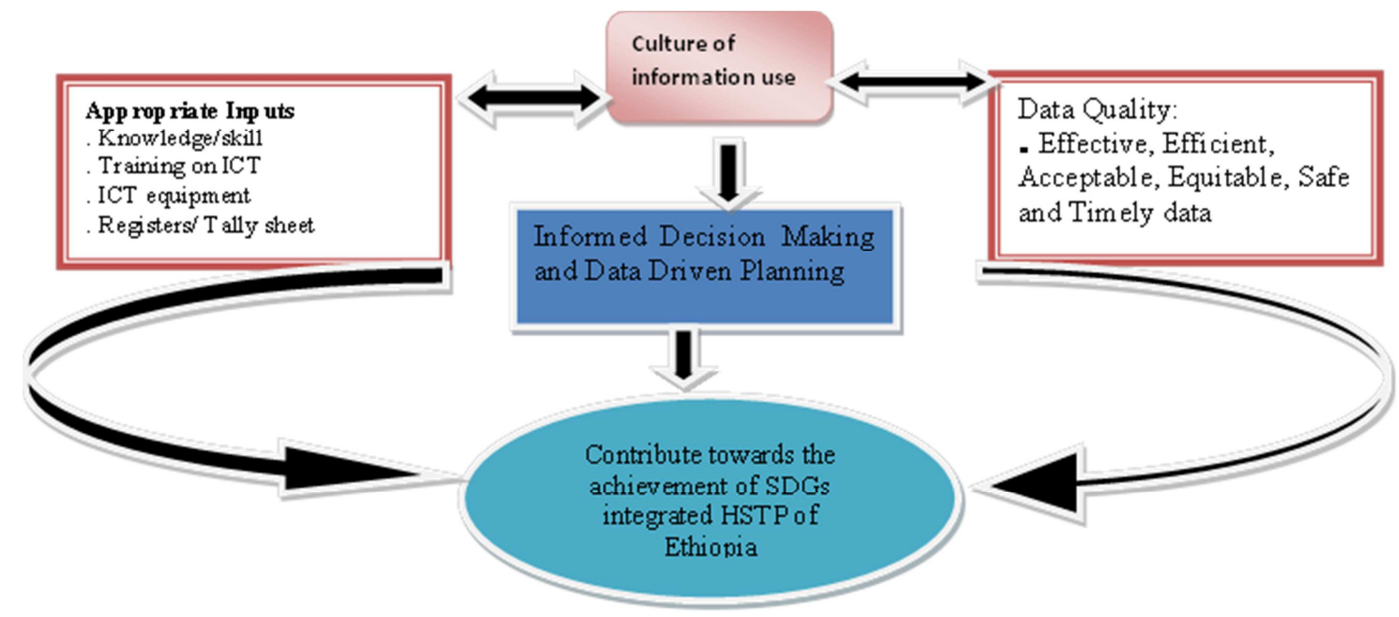

Figure 1. Conceptual frame work developed after reviewing literatures, 2017.

\section{Methods and Materials}

The study was conducted in randomly selected Western Oromia Hospitals of Ethiopia in 2017. A descriptive health facility based cross-sectional study design was employed. The data was collected using quantitative and qualitative data collection method. All health professionals found in governmental Hospitals of Western Oromia, Ethiopia were used as source population. Amongst, health professionals who were working in randomly selected seven government Hospitals of Western Oromia with more than six months were included.

The sample size was calculated using single population proportion formula where, proportion of health professional that implemented HMIS was taken as $50 \%(\mathrm{p}=0.5)$ since there was no similar studies in the area and to fix large sample size, $95 \%$ confidence interval $(Z=1.96)$, margin of error $(\mathrm{d}=0.05), 10 \%$ for potential non-response added and multiplied by two for design effect. Accordingly, the final sample calculated was found to be 620 . The total sample was proportionally allocated to selected seven hospitals based on the size of healthcare worker. Finally, the study populations were selected by using simple random sampling technique.

The study relied on both qualitative and quantitative data from different sources. The quantitative data was collected using structured questionnaire adapted from different studies and modified to fit the local context. The questionnaire was focused on socio-demographic, IT equipment/ facilities, problems encountered in relation to HMIS use and challenges in relation to HMIS implementation. Moreover, qualitative data was collected by in-depth interview with selected key informants (Medical directors of Hospital and HMIS focal person) using interview guide and by observation of Hospitals using observation checklist developed. Prior to data collection, a pretest was conducted to ensure clarity of questions on $5 \%$ of the total sample size, 620 , out of study area. Seven data collectors and seven supervisors were recruited and trained for 2 days on the objective of the study. At the end of each day, the questionnaire was checked for completeness and consistency by the supervisors.

Before data entry identification number was given for all questionnaires. Quantitative data were entered using EPIDATA version 3.0 and exported to SPSS version 17.0 for further analysis. Proportions and numbers were used for description of the results. Univariate descriptive statistics, bivariate regression and multivariate regression were worked out. Accordingly, 95\% confidence interval and P- value less than or equal to 0.5 was used to judge statistical significance association between the dependent and independent variables. The qualitative data of in-depth interview was transcribed, analyzed thematically and triangulated with quantitative data. Ethical clearance was taken from Jimma 
University College of natural science ethical review committee. A support letter was taken from respective Hospitals. In addition, all participants were requested for their informed consent to take part in this study.

\section{Result}

\subsection{Socio-demographic Characteristics}

From the total 620 sampled population 569 were participated with overall response rate of $91.8 \%$. Of the total 569 respondents, 415 (72.9\%) were male. Three hundred fifty $(55.4 \%)$ of the respondents age was below 30 years old. Regarding the level of education 271 (47.6\%) were diploma holders and $263(46.2 \%)$ of the respondents were nurses of all type see table 1 .

Table 1. Socio-demographic characteristics of Health professionals in western Oromia Hospitals, 2017.

\begin{tabular}{llll}
\hline Characteristics & & Number & $\begin{array}{l}\text { Percent } \\
\text { (\%) }\end{array}$ \\
\hline \multirow{3}{*}{ Age category } & <30 & 315 & 55.4 \\
& $>51$ & 182 & 32.0 \\
Gender & Male & 72 & 12.7 \\
& Female & 415 & 72.9 \\
& Oromo & 154 & 27.1 \\
Ethnicity & Amahara & 441 & 77.5 \\
& Tigre & 86 & 15.1 \\
& Others & 24 & 4.2 \\
Level of & PHD & 18 & 3.2 \\
education & Medical/Dental Doctor & 4 & .7 \\
& BSC Degree & 227 & 11.8 \\
& Diploma & 271 & 49.9 \\
Role of health & Chief Executive Officer & 7 & 1.2 \\
professionals & Clinical Director & 7 & 1.2 \\
& Department Head & 100 & 17.6 \\
Number of & Technical Worker & 455 & 80.0 \\
patient health & 10-40 & 280 & 50.6 \\
professionals & 41-60 & 173 & 31.4 \\
attend per day & 61-100 & 55 & 9.9 \\
& >100 & 45 & 8.1 \\
Professional & General Practitioner and or & 74 & 13.0 \\
back-ground & Specialist & 22 & 3.9 \\
& Dentistry & 263 & 46.2 \\
& Nurse all type & 46 & 8.1 \\
& Pharmacist & 55 & 9.7 \\
& Health Officer & 44 & 7.7 \\
& Others & 65 & 11.4 \\
\hline
\end{tabular}

\subsection{Availability of HMIS Center and Facilities in the Hospital}

Of the total respondents $541(95.1 \%)$ reported that, they were aware of presence of HMIS center in their hospital. In this study, only $97(17.0 \%)$ of participants reported there was access to computer in their respective departments to record information of the patients. Similarly, only $39(6.9 \%)$, and 23 $(4.0 \%)$ of the health professionals reported there was access to printer and video-conferencing facility respectively. Majority of the respondents, $485(85.2 \%)$, were aware of the presence of annual plan related to HMIS in their hospital. However, only one-third $(32.2 \%)$ of the health professionals indicated they were participated in the planning process. See table 2 .

Table 2. Availability of Required Resources for HMIS Program Practice in western Oromia Hospitals, 2017.

\begin{tabular}{|c|c|c|c|}
\hline Characteristics & & Number & Percent (\%) \\
\hline \multirow{2}{*}{ Access to computer } & Yes & 97 & 17.0 \\
\hline & No & 472 & 83.0 \\
\hline \multirow{2}{*}{ Access to printer } & Yes & 39 & 6.9 \\
\hline & No & 530 & 93.1 \\
\hline \multirow{2}{*}{$\begin{array}{l}\text { Access to telephone land } \\
\text { line }\end{array}$} & Yes & 306 & 53.8 \\
\hline & No & 263 & 46.2 \\
\hline \multirow{2}{*}{ Access to internet } & Yes & 87 & 15.3 \\
\hline & No & 482 & 84.7 \\
\hline \multirow{2}{*}{$\begin{array}{l}\text { Access to video } \\
\text { conferencing }\end{array}$} & Yes & 23 & 4.0 \\
\hline & No & 546 & 96.0 \\
\hline \multirow{3}{*}{$\begin{array}{l}\text { Presence of computerized } \\
\text { program/ software for } \\
\text { generating report }\end{array}$} & Yes & 154 & 27.1 \\
\hline & No & 352 & 61.9 \\
\hline & I don't know & 63 & 11.1 \\
\hline \multirow{4}{*}{$\begin{array}{l}\text { Aware the presence of } \\
\text { HMIS center } \\
\text { Aware presence of annual } \\
\text { plan for HMIS }\end{array}$} & Yes & 541 & 95.1 \\
\hline & No & 28 & 4.9 \\
\hline & Yes & 485 & 85.2 \\
\hline & No & 84 & 14.8 \\
\hline \multirow{2}{*}{$\begin{array}{l}\text { Participation in the planning } \\
\text { process }\end{array}$} & Yes & 183 & 32.2 \\
\hline & No & 386 & 67.8 \\
\hline
\end{tabular}

\subsection{Implementation of HMIS and Major Challenges Among Health Professionals in Western Oromia Hospital}

\subsubsection{Implementation of HMIS}

Of the total respondents $504(88.6 \%)$ were ever implemented HMIS to collect patient data in their hospital. Of which, only $85(16.9 \%)$ of the respondents perceived that they regularly analyze and change the collected data in to meaningful information. However, 221 (43.8\%) of the participants reported they use output of HMIS generated information for different purpose. Of which 138 (62.4\%), 30 $(13.6 \%)$, and $53(24.0 \%)$ of the health professionals were using for reporting to next level, planning, and decision making respectively. See table 3 .

Table 3. Implementation and HMIS plans and tools for implementation among health professionals in western Oromia Hospitals, 2017.

\begin{tabular}{|c|c|c|c|}
\hline Characteristics & & Number & $\begin{array}{l}\text { Percent } \\
(\%)\end{array}$ \\
\hline \multirow{2}{*}{ Ever implemented HMIS } & Yes & 504 & 88.6 \\
\hline & No & 65 & 11.4 \\
\hline \multirow{4}{*}{$\begin{array}{l}\text { Regularly analyze and } \\
\text { change the collected data in } \\
\text { to meaningful information } \\
\text { Use output of HMIS } \\
\text { generated information }\end{array}$} & Yes & 85 & 16.9 \\
\hline & No & 419 & 83.1 \\
\hline & Yes & 221 & 43.8 \\
\hline & No & 283 & 56.2 \\
\hline \multirow{3}{*}{$\begin{array}{l}\text { HMIS generated } \\
\text { information is used for }\end{array}$} & $\begin{array}{l}\text { Reporting to next } \\
\text { level }\end{array}$ & 138 & 62.4 \\
\hline & Planning & 30 & 13.6 \\
\hline & Decision making & 53 & 23.4 \\
\hline
\end{tabular}

\subsubsection{Major Challenges for Implementing HMIS}

The major challenges facing in relation to the consistent implementation of HMIS were shortage of trained human power in HMIS 158 (31.3\%), inadequacy of HMIS tools 89 (17.7\%), incomplete data filling 174 (34.5\%), poor 
monitoring and evaluation $32(6.4 \%)$ and poor feedback system $51(10.1 \%)$ see figure 2 . Moreover, a medical director of hospital said “... many people equate HMIS with filling endless registers with names and addresses of patients, compiling information on disease every week or every month and sending out reports. Even though, the data generated are often not helpful for management decision making because records are incomplete, in accurate and untimely. In other words, HMIS tend to be data driven instead of action driven".

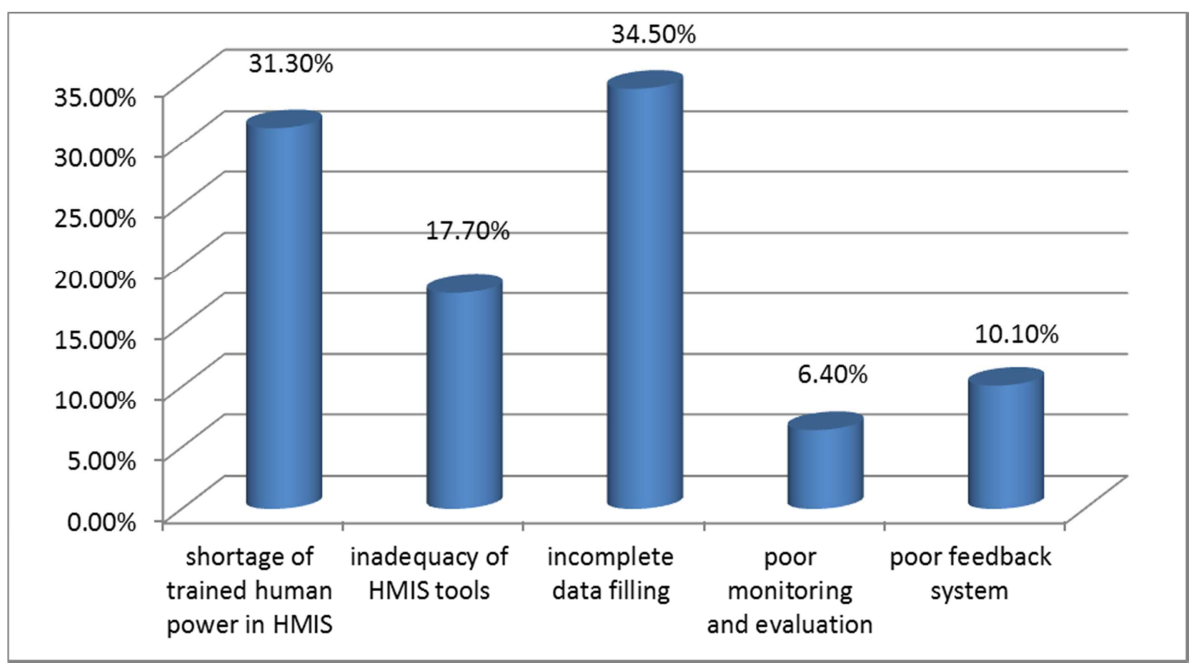

Figure 2. The major challenges facing in relation to the consistent implementation of HMIS in Western Oromia Hospitals 2017.

\subsection{Factors Affecting the Implementation of Health Management Information System Program}

To identify factors affecting implementation of HMIS program variables like adequacy of HMIS reporting formats, monitoring and evaluation, trained human power on HMIS, feedback system, awareness to the presence of annual budget for HMIS and access to computer were entered to bivariate logistic regression and found to be significant at P-value of $<$ 0.25 . Hence, the variables were entered to multivariate logistic regression model in stepwise to identify independent predicators of HMIS implementation. Accordingly, access to computer, and awareness to the presence of annual budget for HMIS found to be insignificant at $(\mathrm{P} \leq 0.05)$. However, there is statistically significant association between consistent implementation of HMIS program and adequacy of HMIS reporting formats, feedback system, monitoring and evaluation and trained human power on HMIS.

Interestingly, it was found that hospitals with adequate HMIS reporting formats were 8 times more likely to consistently implement HMIS program as compared to hospitals with no adequate HMIS reporting formats at $\mathrm{AOR}=$ 8.333 CI $(2.604,27.027)$. Similarly, the presence of regular monitoring and evaluation affected the implementation of HMIS program in the studied hospitals at $\mathrm{AOR}=1.930 \mathrm{CI}$ (1.025, 3.636). Accordingly, hospitals with regular monitoring and evaluation of HMIS program were 2 times more likely to consistently implement HMIS program as compared to their counterparts.

In this study, it was found that there was statistically significant association between implementation of HMIS program and presence of trained staffs on HMIS. Accordingly, hospitals with trained staffs on HMIS were 2 times more likely to implement HMIS program at $\mathrm{AOR}=$ 1.921 CI $(1.803,4.592)$. Moreover, the presence of regular feedback on use of HMIS was found to be one of the factors associated with consistent implementation of HMIS in western Oromia hospitals. Accordingly, hospitals which had regular feedback on performance were 2 times more likely to consistently implement HMIS program as compared to hospitals with no regular feedback at $\mathrm{AOR}=2.018 \mathrm{CI}$ (1.214, 3.357) see table 4. Similarly, this finding was supported by in-depth interview with medical director; who said, "... quarterly and in six month Oromia regional health bureau and zonal health department supervise and give feedback... even if it is not regular; this was life and blood for our implementation of HMIS. On top of that, our hospital had established HMIS unit and data management committee within the hospital which monitor and give feedback to all units of the hospital".

Table 4. Factors affecting implementation of HMIS in western Oromia hospitals, 2017.

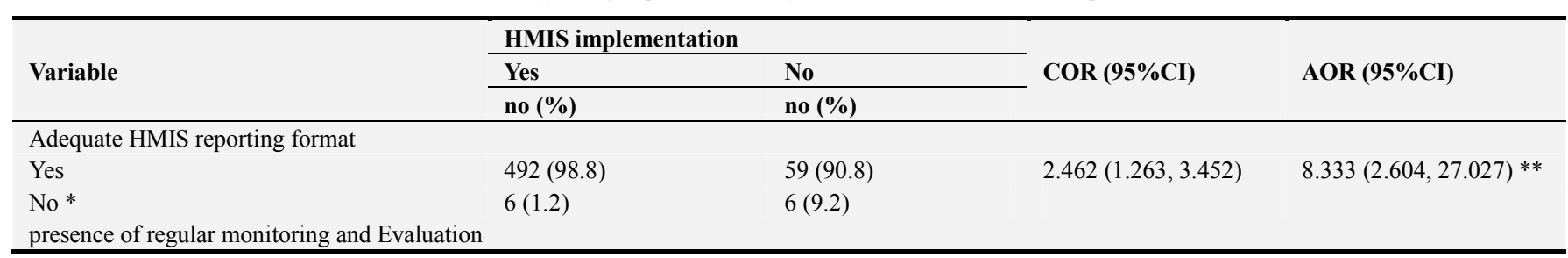




\begin{tabular}{|c|c|c|c|c|}
\hline \multirow{3}{*}{ Variable } & \multicolumn{2}{|c|}{ HMIS implementation } & \multirow{3}{*}{ COR $(95 \% C I)$} & \multirow{3}{*}{ AOR $(95 \% C I)$} \\
\hline & Yes & No & & \\
\hline & no (\%) & no (\%) & & \\
\hline Yes & $67(13.5)$ & $15(23.1)$ & $0.324(1.002,2.352)$ & $1.930(1.025,3.636) * *$ \\
\hline No * & $431(86.5)$ & $50(76.9)$ & & \\
\hline \multicolumn{5}{|c|}{ Access to computer } \\
\hline Yes & $121(24.3)$ & $7(9.9)$ & $0.341(1.152,1.764)$ & $0.467(0.234,1.865)$ \\
\hline No * & $377(75.7)$ & $64(90.1)$ & & \\
\hline \multicolumn{5}{|c|}{ Aware of presence of annual budget for HMIS } \\
\hline Yes & $187(50.4)$ & $8(22.9)$ & $1 . .312(1.214,4.725)$ & $3.424(0.517,7.751)$ \\
\hline No* & $184(49.6)$ & $27(77.1)$ & & \\
\hline \multicolumn{5}{|c|}{ Shortage of trained staffs on HMIS } \\
\hline Yes* & $423(84.9)$ & $65(91.5)$ & & \\
\hline No & $75(15.1)$ & $6(8.5)$ & $1.391(1.261,3.82)$ & $1.921(1.803,4.592)$ ** \\
\hline \multicolumn{5}{|c|}{ Presence of regular feedback } \\
\hline Yes & $276(56.8)$ & $28(39.4)$ & $1.037(0.824,2.629)$ & $2.018(1.214,3.357)^{* *}$ \\
\hline No* & $210(43.2)$ & $43(60.6)$ & & \\
\hline
\end{tabular}

\section{Discussion}

The present study found that more than three fourth of health professionals in western Oromia hospitals were ever implemented HMIS to collect patient data in their hospital. However, less than quarter of the respondents perceived that they regularly analyze and change the collected data in to meaningful information. Furthermore, about one-third of the health professionals reported incomplete data filling as the major challenge for consistent implementation of HMIS in their respective hospital.

Similarly, in-depth interview with medical directors revealed that medical records are incomplete, in accurate and untimely even after implementation of HMIS. This was not in line with the finding from South Africa, which indicated the implementation of HMIS improved data completeness from $26 \%$ before to $64 \%$ after the implementation; and improved overall accuracy of data [7]. The possible explanation for observed discrepancy might be standardizing, simplifying, integrating and institutionalizing of HMIS was different for the two setups due to difference in HMIS reform.

Although, access to the right information at the right time is a crucial ingredient of modern healthcare service [12]; it is not only availability but utilization of information which is a sufficient condition to support informed decision-making and planning [9]. Furthermore, Archangel in 2007 reported, Ethiopian health system is increasingly recognizing the need for more effective and accessible health information for use by service providers, consumers and policy makers by using HMIS as a tool [8].

The purpose of health information services is to provide a link of facilitating access or disseminating health information to assist health professionals and organizations in predicting future needs and making decisions [13, 14]. Additionally, H. E. Dr. Kesetebirhan Admasu former Minister, Federal Ministry of Health, Ethiopia "....health information is much more than collecting figures. Data have no value in themselves; value and relevance come after data management and analysis...the process whereby data are transformed into information and knowledge for action." [17]. In contrary to this more than half of the participants reported they did not use output of HMIS generated information. However, this finding was promising and should be enhanced when compared to the study by Gashaw that showed utilization of information was $22.5 \%$ which was relatively low [10].

HMIS reform in Ethiopia outlined as integrated medical records like individual folder, individual summary sheet and patient card; record management like master patient index and tracer card are important tools for successful implementation of HMIS program [15]. Despite the fact, in this study inadequacy of HMIS reporting tools like tally sheet, individual folders and master patient index were found to be challenge for consistent implementation of HMIS program. The reason for the observed difference might be due to poor leadership, management and governance as reflected by poor implementation. Moreover, the present finding deviate from the report of world bank where HMIS specifically, electronic HMIS can make use of tools like mobile phone-based health (m-Health) applications, telemedicine systems, or eLearning programmes, and includes the digitization of a country's HMIS or Health Information System (HIS) [16].

Almost all of the health professionals reported they were not aware of the presence of annual budget for HMIS program. This finding was in line with the report of federal ministry of health, which stated, there is no budget specifically allocated for the HMIS to fulfill operational cost [6].

This study depicted that, poor monitoring and evaluation, shortage of trained human power and poor feedback system as challenge for consistent implementation of HMIS. This was similar to study conducted in Kenya which reported, collection, processing, analysis and utilization of accurate data at the facility and district levels is of utmost importance in provision of quality care; but the fact that lack of training and poor monitoring hindered the goal [11].

In conclusion, inadequacy of HMIS reporting tools like tally sheet, individual folders and master patient index were found to be challenge for consistent implementation of HMIS 
program. Despite the fact, in this study it was found that information is generated via using HMIS. However, the utilization of the generated information is not the culture in more than half of the studied health care facilities. Furthermore, there is statistically significant association between implementation of HMIS program and presence of adequate HMIS tool, trained human power in HMIS, monitoring and evaluation and feedback system.

Based on the findings of this study, it is recommended that, Hospital management board should devise strategies like using of internal revenues generated to fulfill HMIS reporting format for consistent implementation. Moreover, training of staffs, monitoring and evaluation and feedback system should be strengthened for successful and sustainable implementation of HMIS program.

\section{Abbreviations}

FMOH: Federal Ministry of Health

HIS: Health Information System

HMIS: Health Management Information System

HSDP: Health sector Development Program

ICT: Information Communication Technology

SDG: Sustainable Development Goal

\section{Authors' Contributions}

TA, SS and SS designed and oversee the study and performed the statistical analysis. TA wrote the manuscript. SS and SS proposed suggestions to improve the study and revised the manuscript. All authors read and approved the final manuscript.

\section{Acknowledgements}

The authors would like to thank data collectors and supervisors for their meticulous effort exerted in data collection. We are also very grateful to Jimma University College of Natural Science for funding the research as part of mega research project number CNS/285/09. of the participants of the survey for their cooperation and thank Jimma University College of Natural sciences for funding the research.

\section{Competing Interests}

The authors declare that they have no competing interests.

\section{References}

[1] L. Theo, S. Rainer. A framework for designing Health Information Systems, 2000. Available at: http://libdoc.who.int/publications/2000/9241561998_(chp2).p df. Accessed, March 7, 2014.
[2] SD. Makombe, M. Hochgesang, A. Jahn, H. Tweya, B. Hedt, S. Chuka, JK. Yu, J. Aberle Grace, O. Pasulani, C. Bailey, K. Kamoto, EJ. Schouten, AD. Harries. Assessing the quality of data aggregated by antiretroviral treatment clinics in Malawi. Bull World Health Organ. 2008. 86: 310-314.

[3] MOH. Health Policy of the Transitional Government of Ethiopia, FMOH 1993.

[4] MOH. Health Management Information System (HMIS) /Monitoring and Evaluation (M\&E) Strategic Plan for Ethiopian Health Sector. Federal Ministry of Health, 2008.

[5] A. Garrib, N. Stoops, N. McKenzie, L. Dlamini, T. Govender, J. Rohde, K. Herbst. An Evaluation of the District Health Information System in rural South Africa. S Afr Med J. 2008. 98: 549-552.

[6] MOH. Assessment of the Ethiopian National Health Information System. Federal Ministry of Health, 2007.

[7] W. Mphatswe, KS. Mate, B. Bennett, H. Ngidi, J. Reddy, PM. Barker, N. Rollins. Improving Public health information: a data quality intervention in Kwazulu-Natal, South Africa. 2012. Bull World Health Organ 90: 176-182.

[8] N. Archangel. The Critical Issues Affecting the Introduction of Health Management Information Systems in Developing Countries in Africa, 2007. Thesis Master Informatiekunde Programma Business Information Systems Universiteit van Amsterdam Faculteit Natuurwetenschappen Wiskunde en Informatica en Faculteit Economie en Bedrijfskunde.

[9] T. Nutley, S. McNabb and S. Salentine. Impact of a decisionsupport tool on decision making at the district level in Kenya. Health Research Policy and Systems. 2013, 11: 34.

[10] A. Gashaw. Assessment of Utilization of Health Information System at District Level with particular Emphasis to HIV/AIDS program in North Gondar Zone Amhara National regional State. 2006. MSc. Thesis. Addis Ababa: Community Health: Addis Ababa University.

[11] Ministry of Health of Kenya. Health Management Information System of Kenya- a Report on the performance Status. 2008.

[12] Nicholas, D. et al. Searching intention and information outcome: a case study of digital health information. 2001, Libri, vol. 51, no. 157, pp. 166.

[13] Bawden, D. \& Blakeman, K. IT strategies/or information management", Butterworth, London. 1999.

[14] Dubow, J. Improving health, connecting people: the role of ICTs in the health sector of Developing countries. 2006.

[15] Jhpiego. Beyond survival: Ensuring quality of healthcare for all. Jhpiego annual report, 2014.

[16] Christine Z, Masatake Y, Vicky H, Robin M, and Daniel A. Mobile Applications for the Health Sector. ICT Sector Unit World Bank, 2012.

[17] Federal Ministry of Health. HMIS Information Use Guide: Technical Standards Area 4: Version 2013. 